\title{
How Have Travelers Changed Mode Choices for First/Last Mile Trips after the Introduction of Bicycle-Sharing Systems: An Empirical Study in Beijing, China
}

\author{
Aihua Fan, ${ }^{1}$ Xumei Chen $\mathbb{D}^{1,2}$ and Tao Wan ${ }^{3}$ \\ ${ }^{1}$ Key Laboratory of Transport Industry of Big Data Application Technologies for Comprehensive Transport, Ministry of Transport, \\ Beijing Jiaotong University, Beijing 100044, China \\ ${ }^{2}$ Xuchang University, Xuchang, Henan 461000, China \\ ${ }^{3}$ Beijing Capital International Airport, Beijing 100621, China
}

Correspondence should be addressed to Xumei Chen; xmchen@bjtu.edu.cn

Received 4 January 2019; Revised 27 March 2019; Accepted 30 April 2019; Published 14 May 2019

Academic Editor: Oded Cats

Copyright (c) 2019 Aihua Fan et al. This is an open access article distributed under the Creative Commons Attribution License, which permits unrestricted use, distribution, and reproduction in any medium, provided the original work is properly cited.

\begin{abstract}
In recent years, there has been rapid development in bicycle-sharing systems (BSS) in China. Moreover, such schemes are considered promising solutions to the first/last mile problem. This study investigates the mode choice behaviors of travelers for first/last mile trips before and after the introduction of bicycle-sharing systems. Travel choice models for first/last mile trips are determined using a multinomial logit model. It also analyzes the differences in choice behavior between the young and other age groups. The findings show that shared bicycles become the preferred mode, while travelers preferred walking before bicycle-sharing systems were implemented. Gender, bicycle availability, and travel frequency were the most significant factors before the implementation of bicycle-sharing systems. However, after implementation, access distance dramatically affects mode choices for first/last mile trips. When shared bicycles are available, the mode choices of middle-aged group depend mainly on gender and access distance. All factors are not significant for the young and aged groups. More than $80 \%$ of public transport travelers take walking and shared bicycles as feeder modes. The proposed models and findings contribute to a better understanding of travelers' choice behaviors and to the development of solutions for the first/last mile problem.
\end{abstract}

\section{Introduction}

The first/last mile trips have been paid enough attention because of the important role they play in promoting public transport seamless connection with travel origins/destinations. The first/last mile problem that can be defined as the challenges caused by the built and social environment [1] and public transport service availability in the first/last leg of the trip generally exist in different worldwide cities. The built and social environment includes land use mix, neighborhood design, distance from and to public transportation, employment opportunities, and other related factors. The problem not only influences travelers' mode choices for an entire trip but also affects how transit users arrive at their boarding stations or destinations after alighting from public transit stations [1]. Although some countermeasures have been taken to solve this problem, such as improving the built environment and providing minibus services for those areas that regular bus services cannot reach, it is still an extensive issue. Because it is limited by physical conditions (such as road widths and a lack of bus terminals), transit agencies have difficulties in providing better feeder services for first/last mile trips. Other transportation modes, especially nonmotorized transport systems [2], could be improved to complement the travel service in the hindered areas of public transport and thereby provide convenient transfers to public transportation.

In the last few decades, automobile ownership has increased significantly in China. Consequently, traffic congestion and traffic pollution problems have arisen. In response to these problems, regulations that restrict automobile purchase and usage have been introduced and applied in 
some of China's cities. Bicycle as a sustainable travel mode began to be advocated. Bicycle-sharing programs including public and private bicycle-sharing systems were initiated under this circumstance.

Beijing public bicycle-sharing system, launched in 2012, had attracted 410,000 subscribers and 94,000 trips each day on average by the end of 2016 [3]. In 2015, private bicyclesharing systems developed quickly in China. By June 2018, 165 cities in China had private bicycle-sharing systems operated by the Mobike Company [4], one of the most well-known bicycle-sharing businesses. In 2017, more than 2 million shared bicycles were introduced into Beijing, attracting 11 million subscribers. Approximately 7 million trips were taken using shared bicycles each day [5]. According to a White Paper survey, market share of bicycle traveling in China has increased from $5.5 \%$ to $11.6 \%$; moreover, automobile travel has decreased from $29.8 \%$ to $26.6 \%$ since bicycle-sharing systems were implemented [6]. It is speculated that, to some extent, the introduction of shared bicycles has contributed to the alleviation of traffic congestion and the promotion of sustainable transport for short-distance travel [7].

Compared with private bicycles, bicycle-sharing systems avoid the issue of bicycle theft and provide more flexible services. With the rapid development of such schemes, travelers' choices for trips are becoming more numerous and convenient, especially for short-distance trips. This study is conducted to understand travelers' preferences for shared bicycles more clearly and measure the change in travelers' mode choices for first/last mile trips after the introduction of bicycle-sharing systems. The primary contributions of this paper are in exploring how shared bicycles affect traveler's mode preference for first/last mile trips through survey design and travel behavior modelling, determining the important factors for shared bicycle use, and providing insights for bicycle-sharing systems and bicycle-transit integration improvement.

The rest of this paper is organized as follows. Section 2 presents a literature review of recent research on sharedbicycle schemes, in particular the influence of shared bicycles on travelers' choice behaviors. The research design, including the city context, data collection, and methodology, is presented in Section 3. Section 4 shows the modelling results, findings, and policy implications. Section 5 provides the conclusion and discusses the scope for future studies.

\section{Literature Review}

This section includes a literature review of the first/last mile problem, integrated network design and solutions, sharedbicycle characteristics, the influence of bicycle-sharing systems on travelers' choice behaviors, and benefits from cycling-transit integration.

Public transport provides a long-distance traveling service; however, it cannot stretch to every corner of a city in the same way as an automobile. As a result, the first/last mile problem is common due to the limited connectivity and flexibility of traditional public transit. Numerous researches on transit network design integrating flexible transit with fixed-route transit [8-11] have been carried out and flexible transit services have been applied to offer alternatives for first/last mile feeder services [11]. However, from the environmental and economical perspective, bike-and-ride seems to offer the most cost-effectiveness and long-term potential to the park-and-ride and feeder bus [12]. With the rapid development of shared economy and the big success of shared bicycles, bicycle-sharing systems have been promoted to solve first/last mile problems and as a substitute mode of motor vehicles in short-distance trips. One of the most critical steps is to ensure the perfect integration between bicycle and transit network. In the past decades, there are growing studies about bicycle network design including bicycle paths and stations considering its integration with public transit services. Lin et al. [13] proposed a mathematical model for bicycle system strategic plan, which considers both the travelers' and investors' cost and service level. The design incorporates the bike lanes, number and location of bicycle stations, and travel paths between each origin and destination. But the actual street network was not considered and travel demand was assumed to be normally distributed. Nair and Hooks [14] developed an equilibrium network model to determine the optimal configuration of a vehicle-sharing (including bicycles, cars, or electric vehicles) system. In this model, travel demand was assumed to be fixed. Liu et al. [15] put forward a new public transit network that considers bus and bicycle network design simultaneously rather than designing the two networks separately to make the integrated network more effective. However, few of the network design problems that integrate bicycle and other main transit mode networks considered varying travel demand and real street network configuration. Also, rational travel choice behavior was assumed. These assumptions or conditions are mainly made to decrease the complexity of the model and compute easily.

Despite various difficulties and challenges, practices in solving first/last mile problems have been proven to be successful. According to experiences learned from Europe and Japan, cycling to public transport may be the most promising and cost-effective strategy to promote public transport use and reduce automobile dependence [16]. The benefits of bicycle-public transport integration have been well recognized; for example, it increases accessibility to sustainable transportation, saves the cost of park and ride infrastructures, and improves the neighborhood environment [17].

In 1965, the first generation of bicycle-sharing programs was launched in Amsterdam. The second and third generations were born in 1990s and also launched in Europe. The great success of the third generation of bicycle-sharing programs in Paris (2007) generated enormous interest in the shared-bicycle mode throughout the world. Countries outside Europe including Brazil, Chile, China, New Zealand, South Korean, Taiwan, and USA began to introduce the bicycle-sharing program [18]. Shared bicycles are one of the fastest growing modes of shared mobility and have been increasing in popularity worldwide in recent years. By the end of 2017, more than 23 million shared bicycles were available around the globe and 304 cities in more than 20 countries had implemented bicycle-sharing systems [19]. In 2017, there were more than 20 million shared bicycles in China and 22.1 
million subscribers [20]. More than 200 cities in China have implemented bicycle-sharing systems. The penetration rate of shared bicycles operated by Mobike Company in Beijing reaches $1.5 \%$ (the number of bicycles divided by the number of people in Beijing). According to surveys in America, Australia, Spain, UK, and China [21-23], the average traveling distance by shared bicycles is $3-4 \mathrm{~km}$. More than $60 \%$ of trips by shared bicycles are for commuting. Research also suggests that individual and sociodemographic attributes and the built environment directly influence travel choices among bicycles, automobiles, and public transit [24]. The significant factors include trip distance, gender, automobile ownership, monthly income, and the length of exclusive bicycle lanes.

The introduction of bicycle-sharing systems has significantly influenced travelers' choice behaviors. According to statistical results of Montreal, Toronto, Washington, D.C., and Minneapolis-Saint Paul, percentages of automobile ownership have decreased by $3.6 \%, 2.0 \%, 2.1 \%$, and $1.9 \%$, respectively, as a result of bicycle-sharing system implementation. Moreover, $36 \%, 25 \%, 41 \%$, and $52 \%$, respectively, of shared bicycle users drive less in these four cities [25]. The findings also show that bicycle sharing acts as a better substitute and complement for public transportation in North American cities, depending on the developing level of public transportation systems. Wang and Liu [26] analyze the trend of bicycle integration in USA, using National Household Travel Survey (NHTS) data for 20012009. The evidence indicates that bicycle-transit integration has become more popular over recent years, especially among commuters and for middle/longer-distance travel. Kager et al. proved that cycling-train integration results in higher travel speeds and alternative access stations in Netherlands [27]. In another paper, Kager and Harms [28] proposed the benefits of cycling-transit integration for traveler (travel time savings, avoiding transfers, increased accessibility, etc.), transit operator (more concentrated and organized travel flows, increased passenger flows and activity around main stations, improved effective capacity, etc.), and urban agglomerations (improved accessibility, increased liveliness of public space, and increased national competitiveness). They also took Netherlands as an example and analyze these components, mechanisms, and effects. Based on actual users and trips of bicycle-transit integration, Shelat et al. [29] found that the bicycle-transit combined trip has longer average distance, indicating that the integration mode may be more appropriate for longer trips. Research has also been conducted to demonstrate the impact of public transportation disruption on bicycle-sharing patterns. In London, such disruption has caused total bicycle-sharing trips and their durations to increase by $85 \%$ and $88 \%$, respectively. This finding suggests that bicycle-sharing systems can improve the resilience of public transportation systems effectively when disruption occurs [30]. Campbell and Brakewood find evidence that bicycle sharing in New York decreased bus ridership [31]. Indeed, to some extent, a bicycle-sharing system can be a substitute for public transit. Moreover, the denser the urban environment (density of population and public transit network) is, the greater the number of travelers replacing public transit for shared bicycles is [32]. In summary, bicycleintegration strategies, including bicycle-railway [33], bicyclebus stations [34], and bicycle-metro stations [24, 34], have been surveyed and demonstrated as significant ways to improve urban mobility and facilitate sustainable transportation. Travelers' choice behaviors have also been influenced by bicycle-sharing systems.

Bicycle-sharing systems have become popular in China in the past two to three years. Bicycling as a sustainable travel mode has now returned to cities. Most cities are actively initiating public/private bicycle-sharing programs. The main goals of these programs are to solve the first/last mile problem and improve urban mobility. However, after the introduction of bicycle-sharing systems, how have people's travel choices changed for first/last mile trips and what factors influence the use of shared bicycles? Relatively few studies have addressed these questions. Thus, the specific study questions in this research are as follows.

(1) What choices did travelers make about their first/last mile trips before the introduction of bicycle-sharing systems?

(2) What choices do travelers make about their first/last mile trips after the introduction of bicycle-sharing systems?

(3) What are the differences in the choice behaviors for first/last mile trips before and after the introduction of bicycle-sharing systems?

(4) What are the differences in the choice behaviors for first/last mile trips between young and other age groups?

Beijing is chosen as the case study. The percentage of young adults $(<=30$ years old) shared bicycle users is the highest for all age groups and travel behavior research regarding young adults has been paid great interest due to reporting their different travel behaviors from prior generations. Consequently, the choice behaviors of young adults and the differences with other age groups are specifically studied.

\section{Research Design}

3.1. City Context. Beijing, the capital of China, is one of the most populated cities worldwide. It had a population of 21.71 million by the end of 2017 and covers an area of $16,410 \mathrm{~km}^{2}$. It is divided into 16 municipal districts (see the left side of Figure 1), with $55.7 \%$ of people living in the urban area (the six districts shown in orange in Figure 1) [35]. Beijing is covered by a large public transportation system that has 1028 bus lines [36] and 22 subway lines. In 2017, average daily passenger ridership of bus transit and the subway reached 8.73 million [36] and 10.35 million [37], respectively. The mode share of public transport was approximately $50 \%$ in 2017.

Bicycles had been the dominant travel mode in Beijing until 1990s. In 1986, the bicycle mode share was $62.7 \%$ [38]; however, in 2016, it only accounted for approximately $12 \%$ [39]. The automobile mode share has been increasing in recent years and accounted for more than 30\% in 2016 [39]. The great thing is that the bicycle-sharing system in Beijing has returned and developed quickly in the past few years. In total, 15 municipal districts have implemented public bicycle-sharing systems, operated by the Beijing Municipal Commission of Transport. More than 2 million private shared bicycles are available. Most bicycles are located in bus/subway 


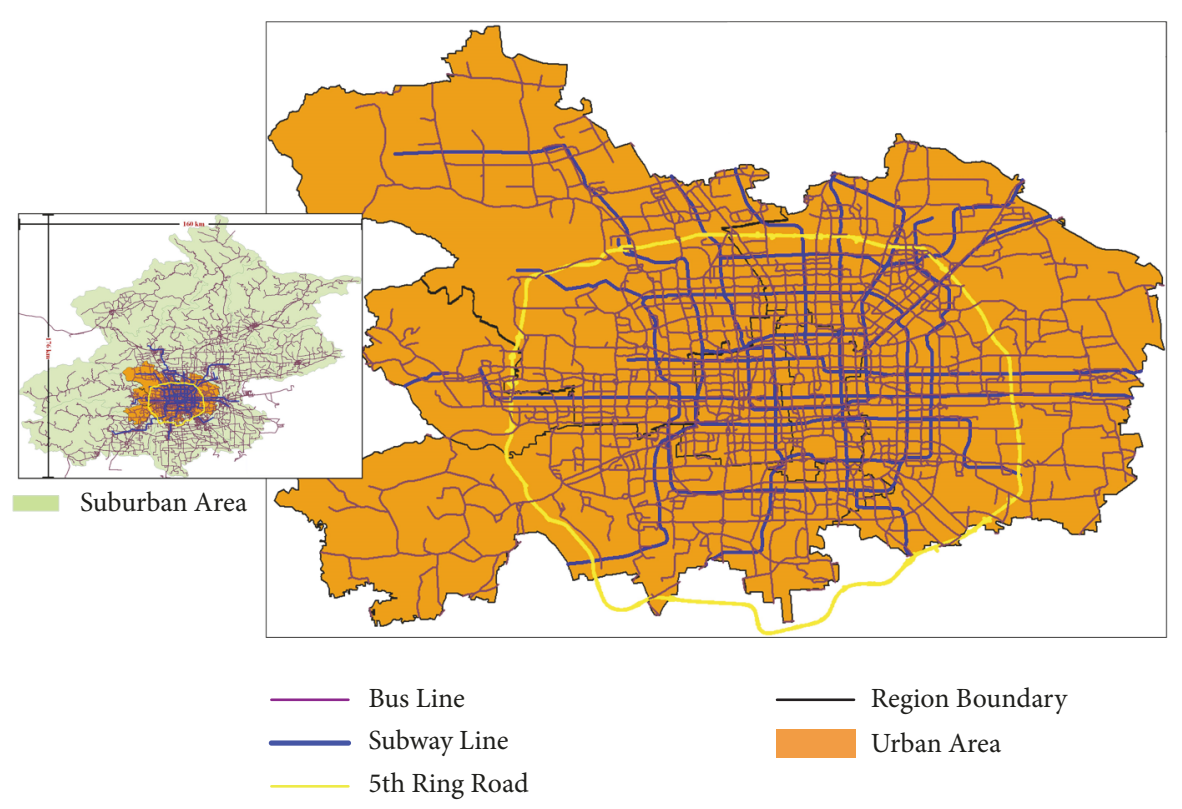

FIGURE 1: Administrative map of Beijing with the bus transit and subway network.

stations and densely distributed in urban areas. As a next step, suburban areas will be considered for the development of bicycle-sharing systems. It is expected that shared bicycles can contribute to improvements in the service level of urban transportation systems and mode transfer to the sustainable transport.

3.2. Data Collection and Statistical Analysis. Figure 2 is the sketch map of an entire trip. We divide the entire trip into three segments: the first mile trip, the public transport trip (hereafter called the "main trip"), and the last mile trip.

We designed a questionnaire to collect travelers' mode choices for first/last mile trips before and after the introduction of shared bicycles. The questionnaire used for modeling has four parts: individual and sociodemographic attributes, travel characteristics, distances related to the built environment, and mode choices for first/last mile trips. Shared bicycle use and improvement suggestions are also included in the end of the questionnaire. Table 1 lists detailed variables of those four parts used for modeling. The travel choices made before and after the introduction of bicycle-sharing systems were collected at one time to ensure uniformity. The questionnaires were issued in April 9-15 and October 15-18 (supplementary investigation) in 2018 through an online and intercept survey in Beijing (scattered all over Beijing). It is about 2.5 years between introduction of the private shared bicycles and the survey. The respondents of the online survey were those who lived in Beijing. We removed those samples where work/house location has changed in recent 3 years to eliminate the error caused by the one-time survey. We obtained 1125 valid questionnaires (1125 respondents), 855 online and 270 intercept. The online survey was conducted by a professional questionnaire company (https://www.wjx.cn/) and the intercept survey was mainly undertaken near bus stops, subway stations, in large communities, on the bus, and in the subway. Note that the questionnaire results reflect the respondents' routine purpose mode choices, not their travel choices for some special or specific activities. For example, if a respondent is employed as a clerk, his/her routine travel purpose every day is going to work. We ask this clerk about her/his mode choice in the recent work traveling. Among these 1125 respondents, 512 take public transport both before and after the bicycle-sharing systems. Because automobile drivers/passengers and active mode users do not have the first/last mile mode choices, we use these 512 samples in travel choice modeling for first/last mile trips. The estimated accuracy at the 95\% confidence interval is $\pm 5 \%$ when the sample size is 384 [40]. Thus, the sample size in this study ensures the robustness of its conclusions.

Table 1 presents the statistical results of 512 samples. Most of the respondents are in the range of $21-50$ years $(88.3 \%)$, live with their partners $(73.5 \%)$, and commute every day (73.9\%). Of the participants, $95.3 \%$ have a bachelor degree or above. Most participants have at least one automobile available (69.8\%); however, only $55.1 \%$ have at least one bicycle available. The majority of participants travel less than $15 \mathrm{~km}(82.8 \%)$ and near $70 \%$ of 1125 samples use sustainable transport (public transport, bicycles, and walking) as their main trip mode. The access and egress distances of first/last mile trips (from origin to nearest public transport stop or from public transport stop to destination) are less than 1 $\mathrm{km}$ for more than $80 \%$ of participants. A significant change occurs within mode choices for first/last mile trips before and after the introduction of shared bicycles. Walking is dominant before (75.3\%); however, after introduction, the mode share of walking decreases to $37.3 \%$, with $45.9 \%$ of participants choosing shared bicycles. In addition, the mode share of private bicycle and automobile decreases slightly. 


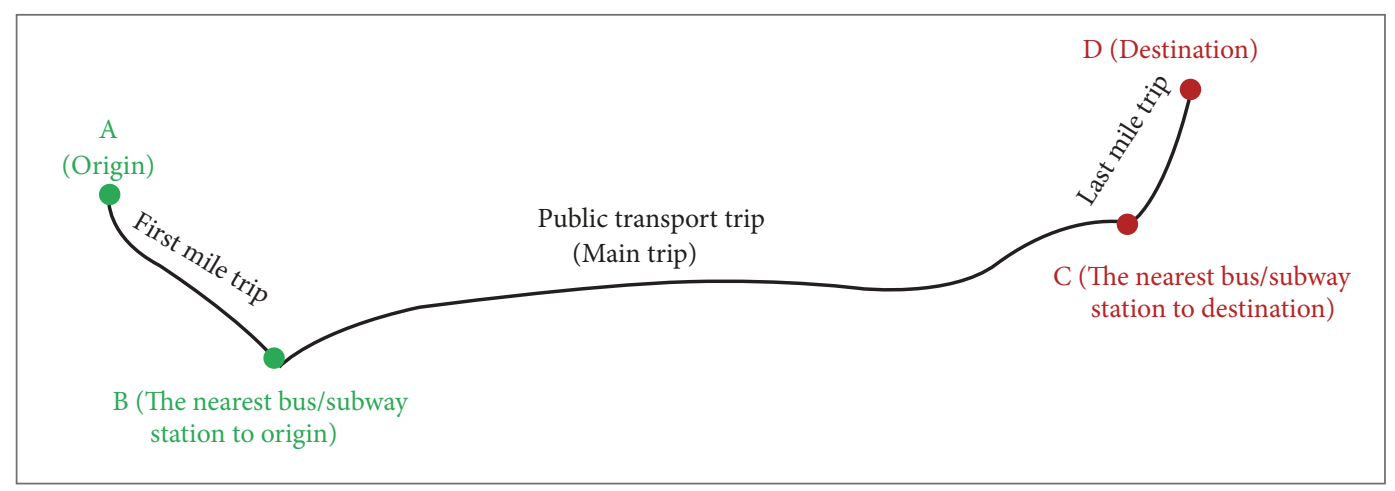

FIgURE 2: The sketch map of an entire trip.

3.3. Methodology. We use the 512 samples of transit users in travel choice modeling for first/last mile trips. Logit model is recognized as the most classical method to model travel choice behaviors. Logit model includes binary and multinomial logit model in accordance with the number of travel choices. In this research, more than two mode choices are considered. Thus, a multinomial logit model is applied to analyze travelers' choice behaviors for first/last mile trips.

Before the introduction of bicycle-sharing systems, travelers had three travel options for first/last mile trips: walking, private bicycles, and automobiles. After the implementation of bicycle-sharing systems, they have four choices: shared bicycles and the three aforementioned choices.

Equation (1) is the conditional probability function of the multinomial logit model. $Y$ equals $0,1,2$, or 3 if travelers choose the walking, shared bicycles, private bicycles, or automobiles, respectively. $\mathrm{P}_{0}, \mathrm{P}_{1}, \mathrm{P}_{2}$, and $\mathrm{P}_{3}$ represent the probabilities that walking, shared bicycle, private bicycle, or automobile modes, respectively, are chosen. $i$ is the number of significant influencing factors and $j$ is available travel options. Vector $\boldsymbol{X}_{\boldsymbol{j} i}$ represents influencing factors for alternative $j$ and $\beta_{j i}$ represents the regression coefficients of different influencing factors.

$$
\begin{aligned}
\mathrm{P}_{\mathrm{j}}=\mathrm{P}\left(Y=j \mid \boldsymbol{X}_{\boldsymbol{j} \boldsymbol{i}}\right)=\frac{\exp \left(\boldsymbol{X}_{\boldsymbol{j} \boldsymbol{i}} \boldsymbol{\beta}_{\boldsymbol{j} \boldsymbol{i}}\right)}{\sum_{j=0}^{3} \exp \left(\boldsymbol{X}_{\boldsymbol{j} \boldsymbol{i}} \boldsymbol{\beta}_{\boldsymbol{j} \boldsymbol{i}}\right)}, \\
\quad i=1,2, \ldots, m ; j=0,1,2,3
\end{aligned}
$$

By transforming (1) and setting $\boldsymbol{\beta}_{\mathbf{0}}=0$, (2) can be obtained. Alternative $j$ with $\boldsymbol{\beta}_{j i}=0$, which is the base category or baseline, provides the reference point for all other travel options. In this research, the walking mode choice is set as the reference point.

$$
\begin{aligned}
\mathrm{P}_{\mathrm{j}}=\mathrm{P}\left(Y=j \mid \boldsymbol{X}_{\boldsymbol{j} \boldsymbol{i}}\right)=\frac{\exp \left(\boldsymbol{X}_{\boldsymbol{j} \boldsymbol{i}} \boldsymbol{\beta}_{\boldsymbol{j} \boldsymbol{i}}\right)}{1+\sum_{j=1}^{3} \exp \left(\boldsymbol{X}_{\boldsymbol{j} \boldsymbol{i}} \boldsymbol{\beta}_{\boldsymbol{j} \boldsymbol{i}}\right)}, \\
\quad i=1,2, \ldots, m ; j=0,1,2,3
\end{aligned}
$$

Equation (3) represents the ratio of the probability of choosing mode $j$ to that of choosing the walking mode. The linear form of the multinomial logit model is shown in (4).
The parameter $\boldsymbol{\beta}_{j i}$ is estimated using maximum likelihood method.

$$
\begin{aligned}
\text { Odds } & =\frac{\mathrm{P}_{j}}{\mathrm{P}_{0}}=\exp \left(\boldsymbol{X}_{\boldsymbol{j i}} \boldsymbol{\beta}_{\boldsymbol{j} i}\right), \quad j=1,2,3 \\
\ln \left(\frac{\mathrm{P}_{\mathrm{j}}}{\mathrm{P}_{0}}\right) & =\boldsymbol{X}_{\boldsymbol{j} \boldsymbol{i}} \boldsymbol{\beta}_{j i}, \quad j=1,2,3
\end{aligned}
$$

\section{Estimation Results and Implications}

In the questionnaire, some variables have too many categories (see Table 1). To avoid some categories with too small sample size, we merge some of them. For example, the number of automobile/bicycles available is divided into two categories: those who have and those who do not. Age is divided into three categories: the young ( $<=30$ years old), middle-aged (31-50 years old), and aged ( $>50$ years old) groups. Next, mode choice models for first/last mile trips before and after the introduction of bicycle-sharing systems are determined. Walking is set as the reference mode for both before and after the introduction of bicycle-sharing systems. Then, travel choice differences between the young and other age groups are conducted. Finally, policy implications are presented in the light of finding results.

\subsection{Travelers' Choice Behaviors for First/Last Mile Trips (before} the Implementation of Bicycle-Sharing Systems). Before the introduction of bicycle-sharing systems, the choice set included automobiles, private bicycles, and walking for first/last mile trips. Table 2 shows the regression results of travel mode preferences. In general, McFadden $\mathrm{R}^{2}$ greater than 0.4 can be interpreted as a very goodness of fit [41]. Studies also have shown that range of $\mathrm{R}^{2}$ in $0.2-0.4$ is acceptable $[42,43]$. The results of model significance test in the left of Table 2 indicate that there is a relatively good fit between the proposed model and the survey data.

For the automobile mode, all the variables are not obviously significant except for the intercept. The intercept is significantly negative, indicating that automobile is extremely unpopular for first/last mile trips when other factors are not considered. More than $95 \%$ of the participants travel less than $2 \mathrm{~km}$ to public transport stops. Walking and bicycles are 


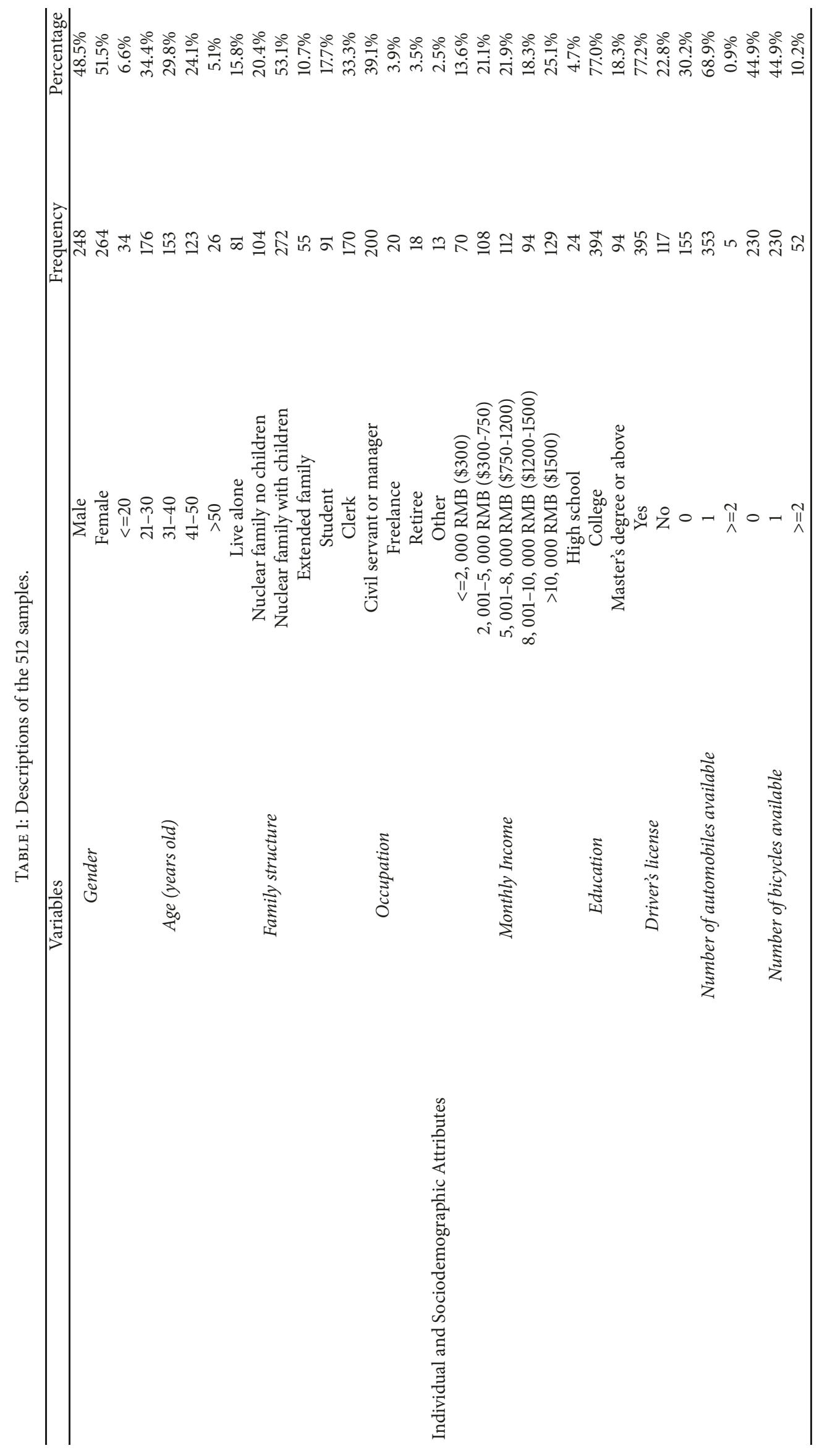




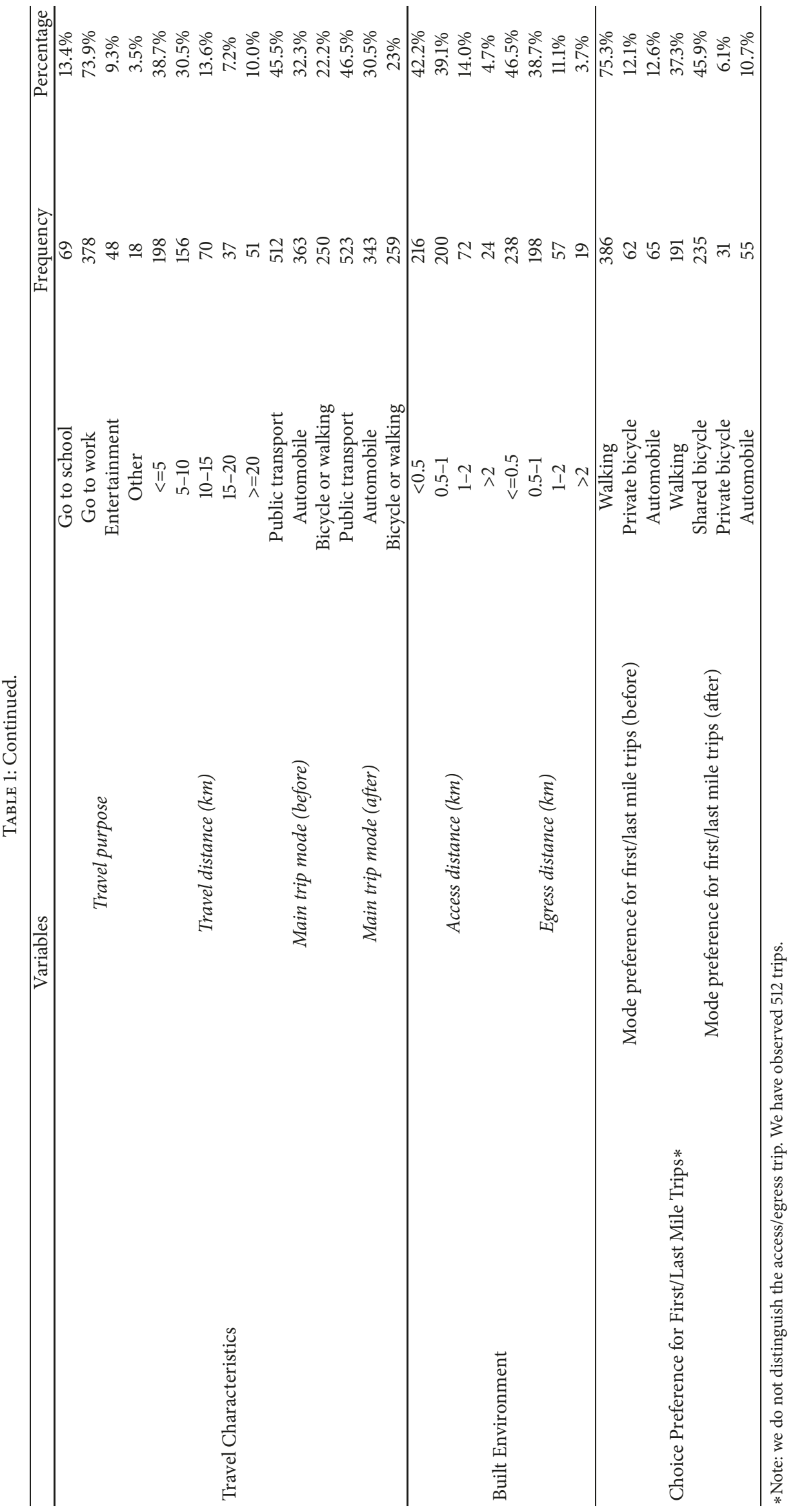




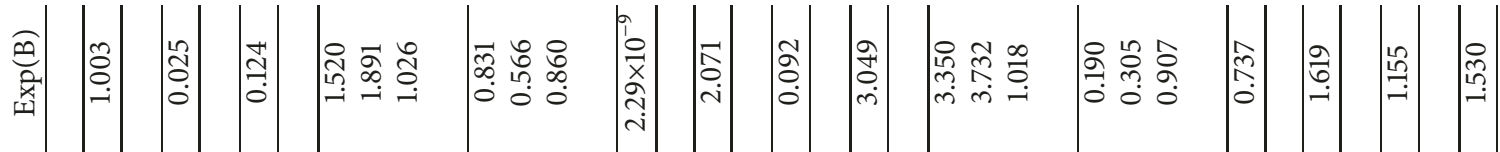

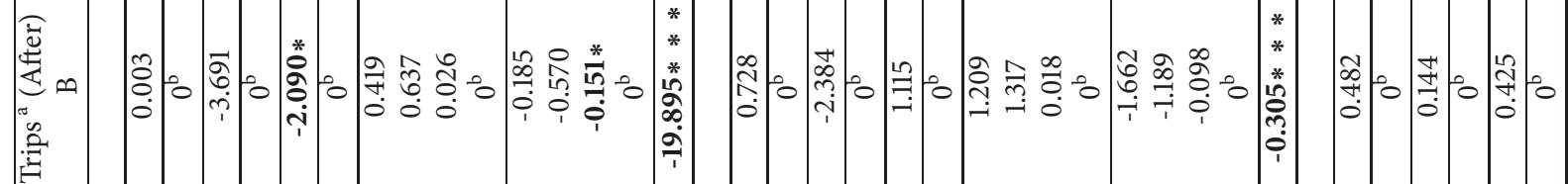

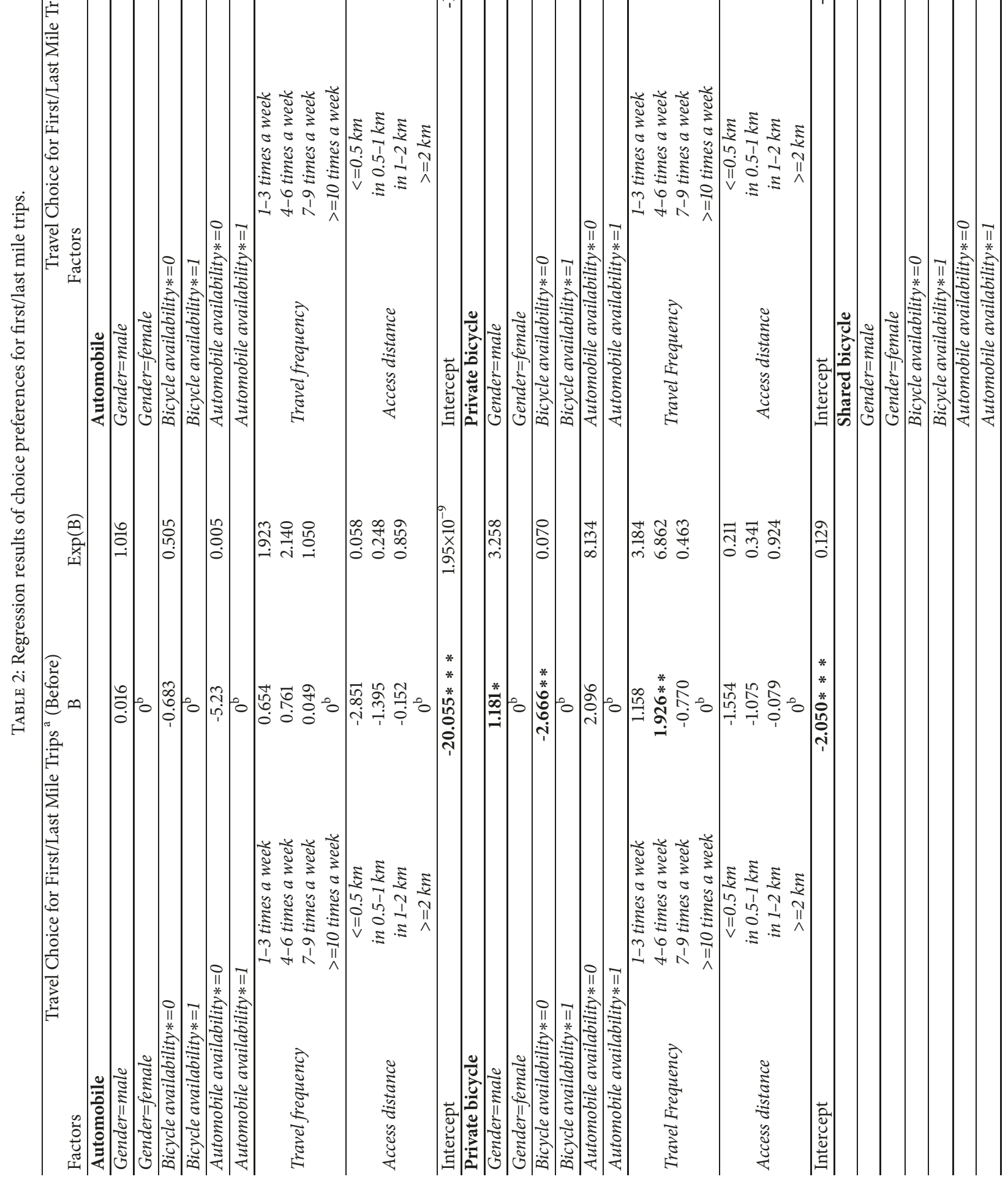




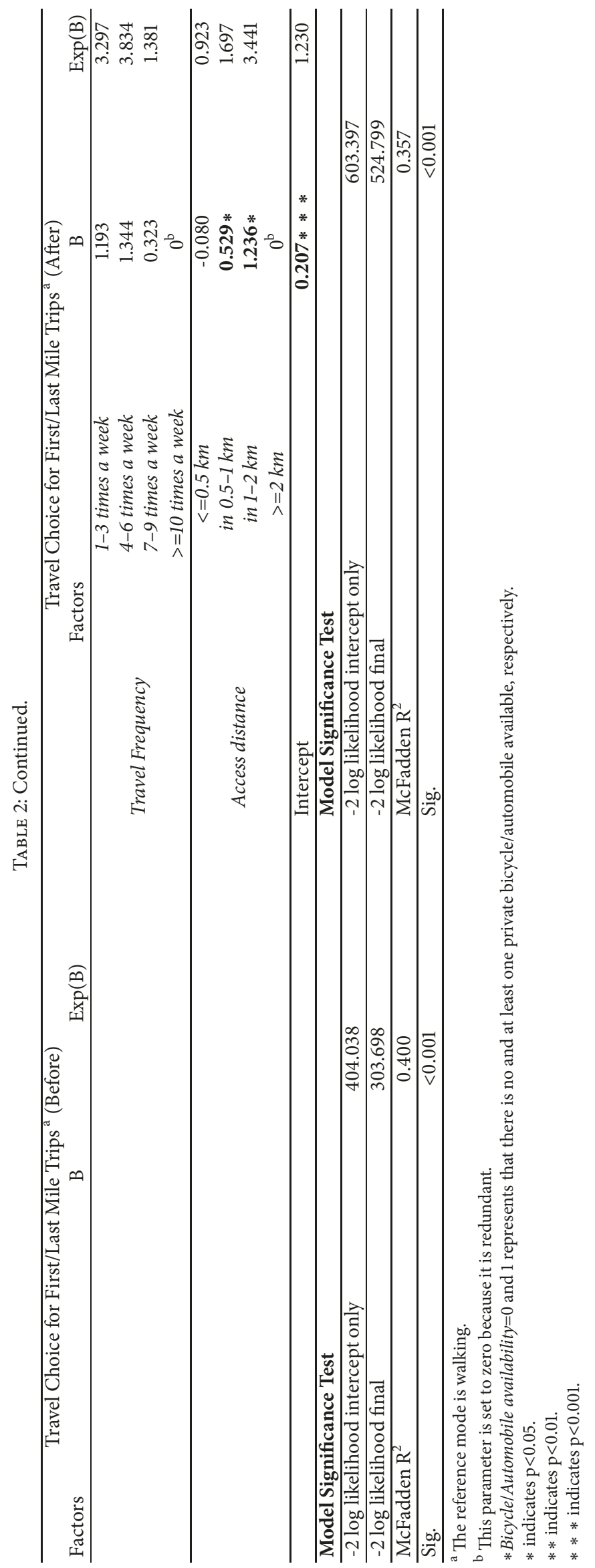


the most appropriate modes for middle- and short-distance traveling [44]. Bicycling or walking is more suitable than traveling by an automobile within $2 \mathrm{~km}$.

For the private bicycle mode, gender, bicycle availability, and travel frequency are significant factors. Males are 3.258 times more inclined to ride a bicycle for first/last mile trips than females. Bicycle availability is distinctively positive in terms of private bicycle use. The influence of travel frequency on private bicycle use is unexpected. The probability of private bicycle use by regularly frequent (4-6 times a week) travelers is 6.861 times greater than that for more frequent travelers ( $>=10$ times a week). The reasons may be that, in Beijing, it is difficult to find dedicated parking areas for bicycles near public transport stations. Most public transport users prefer to walk to stations in case of bicycle stolen or exposed to bad weather, especially for more frequent travelers. The intercept of private bicycle model is still negative, which means that private bicycles are not as popular as walking for first/last mile trips when other factors are not considered.

In sum, walking is the first choice when other factors are not considered. Private bicycle choice is affected by travel frequency and bicycle availability. Male travelers prefer cycling for first/last mile trips compared with females. Automobile is the least likely to be chosen for first/last mile trips.

\subsection{Travelers' Choice Behaviors for First/Last Mile Trips (after} the Implementation of Bicycle-Sharing Systems). The right part of Table 2 shows the estimation results of mode choices for first/last mile trips after the introduction of bicyclesharing systems. McFadden $\mathrm{R}^{2}$ suggests an acceptable fit $\left(\mathrm{R}^{2}=0.357\right)$. Automobile choice behavior for first/last mile trips does not change a great deal. After joining the transportation system, shared bicycles mode share for first/last mile trips is $45.9 \%$; moreover, $93 \%$ of shared bicycle users are from private bicycle or walking mode users. Although most trips by shared bicycles are original walking or private bike trips, it at least reflects on the following two points. (1) Travelers are willing to use shared bicycles. They quickly adapt to the new introduced travel mode and use it in their daily travel. (2) Travel quality for first/last mile trips gets improved. For almost 55\% of the respondents, their traveling distance for first/last mile trips is further than $500 \mathrm{~m}$ (Table 1). This is greater than people's acceptable walking distance. When shared bicycles are available, most people transfer from walking to shared bicycles for first/last mile trips. Also, automobile mode share for the first/last mile trips reduces from $12.6 \%$ to $10.7 \%$ and from $32.3 \%$ to $30.5 \%$ in the main trip. Although a small portion of automobile trips are substituted with shared-bicycle trips, it will still bring great benefits to the people and the environment.

Shared bicycles become the first preference for first/last mile trips (the intercept of the shared bicycle model is positive). Because the shared bicycles in Beijing are widely distributed and travelers can find available bicycles easily, variables such as bicycle availability are not significant any more. When the access distance is further than $500 \mathrm{~m}$, travelers are more inclined to take shared bicycles and travel by automobile when the distance is further than $2 \mathrm{~km}$. People are more sensitive to access distance than egress distance. Travelers's mode choice for first/last mile trips is significantly affected by access distance rather than egress distance.

Main trip mode choices are closely related to individual attributes, travel distance, travel purpose, departure time, characteristics of different modes, and traffic information [45]. Mode choices in the first/last mile trips mainly depend on the access distance, bicycle/automobile availability, travel frequency, and gender. Travelers prefer shared bicycles within $0.5-2 \mathrm{~km}$ over walking. After the introduction of bicyclesharing systems, shared bicycles become the first preferred choice when they are available. The order of preference becomes shared bicycles, walking, private bicycles, and automobiles. This finding demonstrates that shared bicycles are popular among travelers for first/last mile trips and fills the gap in public transport service well.

4.3. Choice Behavior Differences between the Young and Other Age Groups for First/Last Mile Trips. In recent years, travel behavior research regarding young adults has been a topic of great interest. It has been increasingly reported that young adults have quite different travel choice behaviors and lifestyles from those of prior generations. Numerous studies related to young people's automobile ownership and usage [46, 47], migration [48], travel patterns [49], residential locations [50], and multimodal travel behavior [47, 49] have been conducted to explain their behaviors. In the current study, travel choice differences for first/last mile trips between young adults and other age groups are explored to observe the former's behaviors deeply.

4.3.1. Before the Introduction of Bicycle-Sharing Systems. According to regression results with regard to the young group, the important variables for model fitting are bicycle availability and automobile availability. With regard to the middle-aged group, gender, bicycle availability, and access distance are important factors for model fitting.

The ratios of automobile availability for the young and middle-aged people are $58.8 \%$ and $82.9 \%$, respectively (see Figure 3(a)). This difference between them is significant $\left(\chi^{2}(2)=11.13\right.$ and $\mathrm{P}$ value $\left.<0.05\right)$. Because most middle-aged people have automobiles, the automobile availability is not significant in their travel choice modeling. In Figure 3(b), more than $80 \%$ of the young group and nearly $55 \%$ of middleaged people travel by sustainable transportation modes (public transportation, bicycle, and walking) in the main trip. Further, more than $10 \%$ of public transport users take bicycles as their feeder travel mode. Thus, bicycle availability is significant for the young and middle-aged groups. The access distance is considered important among the middle-aged group. Most of the middle-aged people are office workers and have significantly higher income than the young group $\left(\chi^{2}(2)=63.781\right.$ and $\mathrm{P}$ value $\left.<0.01\right)$. They tend to have higher demand for the transportation service and care more about the first/last mile distance when making decisions.

For the aged group, nearly $70 \%$ of them have retired; most of them travel by sustainable transport in the main trip; they mainly travel for discretionary purpose (80\%). All factors are not significant for the aged people. 


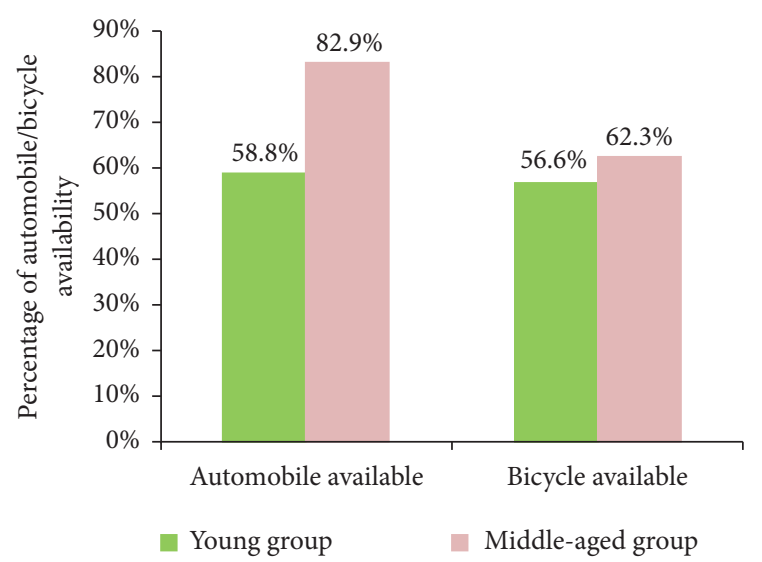

(a)

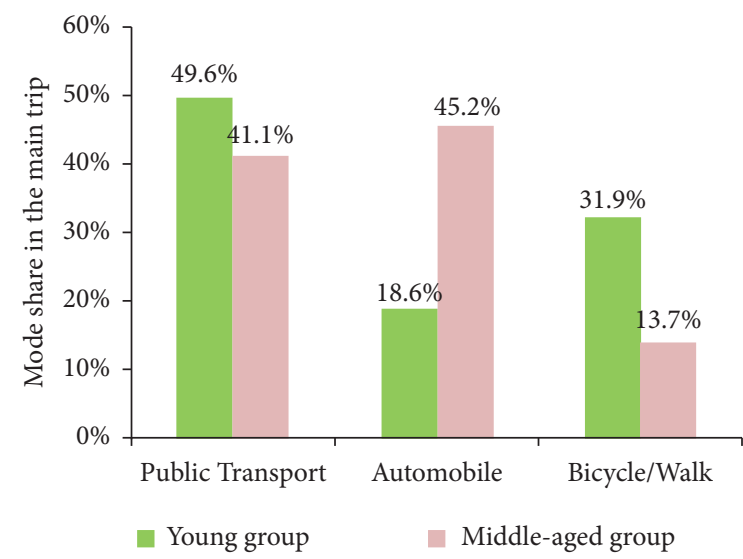

(b)

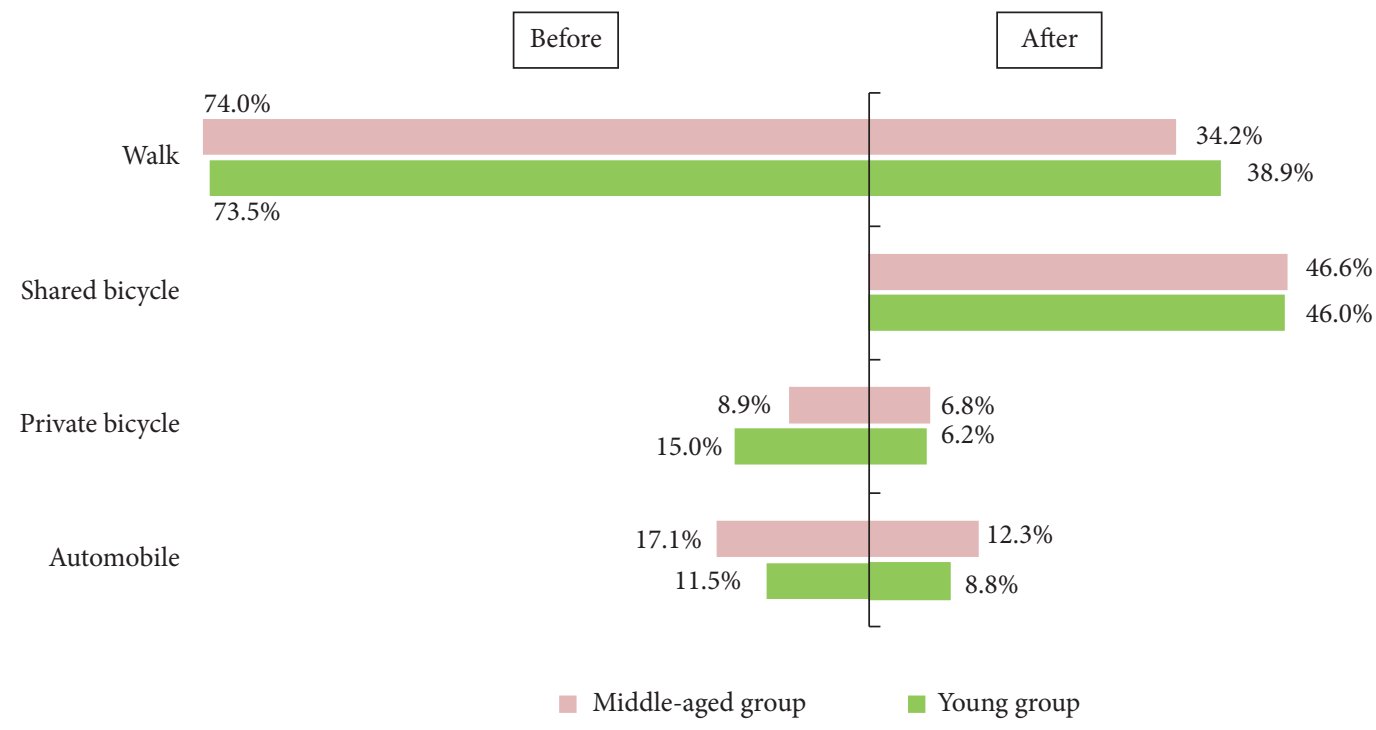

(c)

FIgure 3: (a) Automobile/bicycle availability. (b) Mode choice in the main trip. (c) Mode choice for first/last mile trips before and after the introduction of shared bicycles.

4.3.2. After the Introduction of Bicycle-Sharing Systems. After the implementation of bicycle-sharing systems, more than $85 \%$ of the young public transport travelers take shared bicycles or walking as the feeder mode. No variables are significant determinant factors for their first/last mile mode choice. However, for the middle-aged group, gender and access distance are important factors for first/last mile mode choice. According to Figure 3(c), almost 50\% of travelers from both the young and middle-aged groups transfer to shared bicycles for first/last mile trips. Moreover, the walking mode share decreases sharply. Private bicycle usage for the young group reduces significantly and automobile usage for middle-aged group falls dramatically. Almost an equivalent percentage of participants among young and middle-aged group said they have ever used shared bicycles $(88.5 \%$ and $88.4 \%$ ). However, among the small portion of travelers who have never used shared bicycles, $46 \%$ of the young group said they would not change their choice even though bicycle-sharing systems have improved. The corresponding percentage for the middle-aged group is 35\%. These statistic results indicate that there are small numbers of travelers whose choice behaviors for first/last mile trips are not influenced by bicycle-sharing systems. Such people are mainly automobile and bicycle/walking travelers in the main trip.

All factors are still not significant for the aged group. However, the aged people also have preferences for shared bicycles $(60 \%$ of them choose shared bicycles for first/last mile trips).

4.4. Policy Implications. Policy suggestions are presented here in the light of the findings.

4.4.1. Encourage and Properly Guide the Development of Shared Bicycles. Shared bicycles attract travelers from different generations and occupations. They provide a more convenient travel mode, especially for first/last mile trips. The mode share of shared bicycles is $45.9 \%$; moreover, shared bicycles become the preferred choice for first/last mile trips. According to the survey, nearly $90 \%$ of the participants have 
ever used shared bicycles in their daily trips and more than $40 \%$ of shared bicycle users ride more than four times a week. Shared bicycles fill gaps in public transport effectively in terms of the first/last mile problem and provide a convenient travel mode for short-distance traveling. Moreover, numerous studies have demonstrated that travelers by bicycles or walking have the highest levels of emotional wellbeing [5054]. It should be pointed out that the development of shared bicycles brings some negative effects such as occupying public spaces and affecting urban traffic management because of parking disorderly. In order to prevent the rampant development and implement refined management, the Beijing Municipal Commission of Transport has banned more shared bicycles into market [55]. Other cities, including Shanghai, Shenzhen, Guangzhou, and Hangzhou, have also adopted this kind of policy. Ways exist to facilitate the development of shared bicycles apart from simply increasing their numbers. These ways include more bicycle lanes, improvements to the riding environment, and great priority for cyclists at intersections.

The results demonstrate that travelers are willing to ride a bicycle when it is available, which is a good trend to facilitate sustainable travel. In order to attract more car travelers/passengers to transfer to the bicycle mode, wellperforming bicycle system is necessary. High-quality and refinement management is one of the future trends of shared bicycles. Appropriate encouragement and guide can be provided to the shared-bicycle development.

4.4.2. Improve Bicycle-Sharing Systems. According to the survey, $13 \%$ of participants have never used shared bicycles. Moreover, $58 \%$ of them said that they will use shared bicycles if bicycle-sharing systems are improved. Figure 4 shows the expectations for improvements in bicycle-sharing systems. Most nonusers of shared bicycles (45.5\%) would like to see improvements in bicycle lanes, followed by enhancements of the rental process (40.9\%) and deposit requirement (40.9\%).

Bicycle lanes are the factor they care about most. The problems of the rental process include installing a sharedbicycle application, filling in personal information, and system failure. Everyone can share a bicycle, but the users need to download the application of a shared-bicycle company and register online. When registering, much information including name, address, phone number, ID number, and even banking account if you pay by bank card is needed. It takes 3-5 minutes to finish registration. If the users want to use other shared bicycles operated by another company, they must download another application and register online again. In addition, users are asked to deposit 100-300 RMB (\$15-45) depending on bicycle companies when they register. $94 \%$ of the respondents show that they can find a shared bicycle easily (within 2 minutes) and take about 10 seconds to unlock a bicycle. But when the system fails by chance, it takes more time to unlock or find another bicycle to use. All these are considered obstacles to using shared bicycles. Sharedbicycle distribution (36.4\%), the charge standard $(31.8 \%$, means deposit and cost of each use), and damage rate of shared bicycles (27.3\%) are also regarded as important factors that influence shared-bicycle use. Often, the users need to pay
0.5-1 RMB (\$0.075-0.15) per 30 minutes depending on bicycle companies. The shared-bicycle users almost spend the same cost as the public transport travelers in short trips. Although these findings represent the response from small samples, they nonetheless provide meaningful directions for sharedbicycle development. Improvement in these areas will attract more shared-bicycle users.

4.4.3. Enhance the Service Level of Public Transport and Optimize Transfer Coordination between Bicycle-Sharing/ Pedestrian Walkways and the Public Transportation System. According to Table 1, the introduction of shared bicycles does not greatly influence travelers' mode choice in the main trip. It is not easy to change the travel mode share by simply improving the feeder service for first/last mile trips. Both fast transportation services for the main trip and convenient feeder service for first/last mile trips are critical.

According to the regression results in Section 4.3, different age groups all consider shared bicycles as their prior mode choice for first/last mile trips. After bicycle-sharing systems are introduced, shared bicycles and walking modes account for the highest proportion for first/last mile trips. In the main trip, $45.5 \%$ of the participants travel by public transport, and $45.9 \%$ and $37.3 \%$ of public transport travelers use shared bicycles and walking as their feeder mode, respectively. In order to provide high-quality transportation services for first/last mile trips and make public transport more appealing, more works should be undertaken to coordinate the bike-sharing/pedestrian walkways system for first/last mile trips with the public transportation system in the main trip. According to the survey's results, $42 \%$ of the young group have no automobile available; however, $91 \%$ of them plan to purchase an automobile in the next 10 years, which is really not a desirable trend. It is important to take measures to improve the service level of public transport system and attract more (potential) automobile travelers to public transport. In this survey, 5.5\% of automobile travelers transfer to public transport after the bicycle-sharing systems were introduced. It proves the remarkable effects of bicyclesharing systems on mode choice change to some extent. As a next step, optimizing coordination between bicycle-sharing systems/pedestrian walkways and public transit system has strong significance in facilitating the development of sustainable transport.

\section{Discussions and Conclusions}

Most of China's cities have witnessed rapid development of bicycle-sharing systems in recent years. These schemes complement sustainable transport development and cater to the demands of short-distance traveling. In order to better understand travelers' choice behaviors for first/last mile trips after bicycle-sharing systems are implemented, this study considers the effects of individual attributes, travel characteristics, and the built environment on travel mode choices for such trips. The multinomial logit model is used to model choice behavior and travel choice models for first/last mile trips before and after the introduction of bicycle-sharing systems are established. The choice behaviors of young 


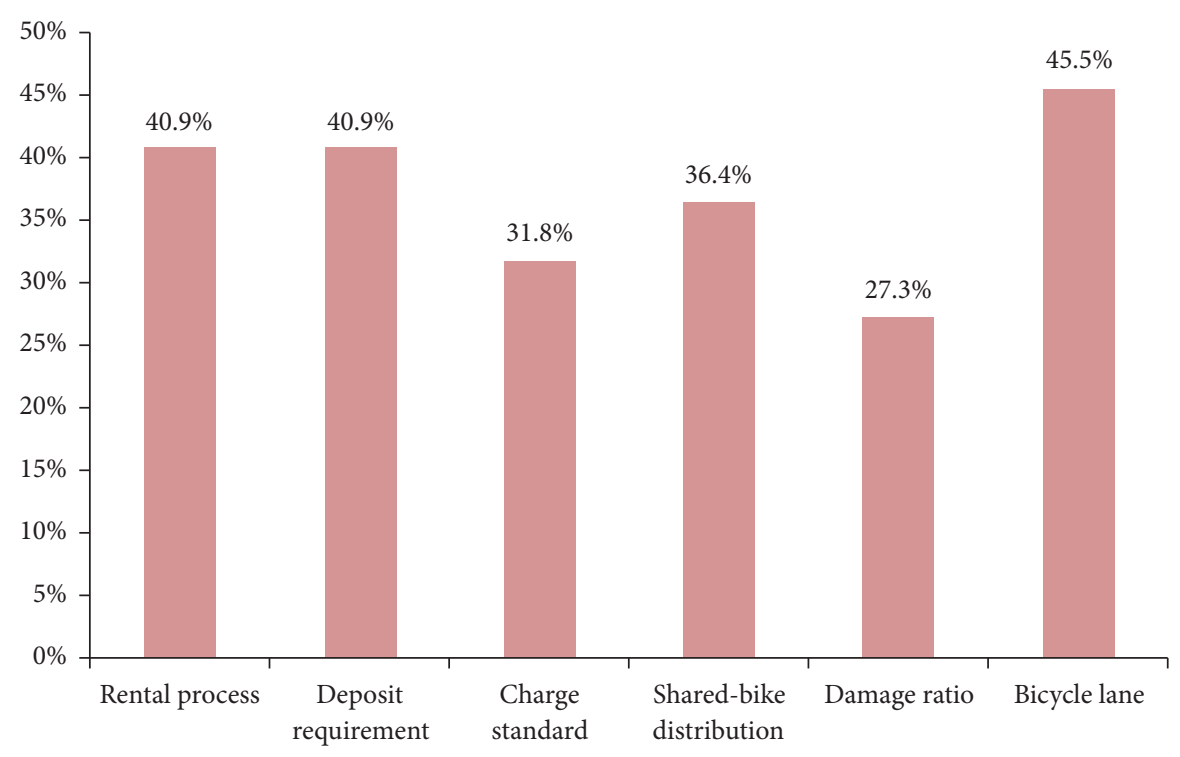

FIgURE 4: Expected improvements for bicycle-sharing systems.

adults are then compared with the other aged groups. Policy suggestions are provided in the light of the finding results.

Before the introduction of bicycle-sharing systems, gender, bicycle availability, and travel frequency are the most significant factors. Walking is the first choice when other influencing factors are not considered. Private bicycle choice is affected by travel frequency and bicycle availability. Male travelers prefer cycling for first/last mile trips compared with females.

After the introduction of bicycle-sharing systems, the mode share of shared bicycles for first/last mile trips reaches $45.9 \%$. Shared bicycles become the first preference, followed by walking, private bicycles, and automobiles.

The important variables are bicycle availability and automobile availability for the young adults when shared bicycles are not available. For the middle-aged group, gender, bicycle availability, and access distance are important factors. When shared bicycles are available, gender and access distance are important factors for the mode choice of middle-aged group. For young and aged people, all the factors are not significant. Shared bicycles and walking are the main feeder modes for different age groups.

This study provides the following insights.

(1) The proposed choice models explain how travelers make mode choices for first/last mile trips and indicate their choice preferences. These findings can help transportation policy-makers better understand travelers' choice behaviors and develop solutions for the first/last mile problem. The solutions include providing shared bicycle service in areas where the access distance to public transport stops is further than $500 \mathrm{~m}$, adjusting the charge standard through asking for users' advices and implementing bike lanes to improve travel experience for first/last mile trips.

(2) Shared bicycles are the preferred choice for first/last mile trips. The proposed models can be combined with travel choice models in the main trip to predict shared bicycle demand and accordingly optimize the scheduling of bicyclesharing systems. When the mode choice modeling in the main trip is determined, the number of public transport travelers at each stop or community can be predicted. Then, according to the mode choice for first/last mile trips, the number of shared bicycle users can be further forecasted. In order to match the number of shared bicycles and the users, the bicycle company can predict the bicycle demand and furtherly put bicycles demanded into market and optimize the operation.

In most other cities of China, the situations of bicyclesharing systems are similar to Beijing. The systems were introduced in recent 2 3 years and experienced disordered expansions. On the surface, we see more alternative mode choices, more sidewalks occupied by bicycles, and deserted bicycles. The bicycle-sharing company and the government are striving for strategies of shared bicycle development. To provide guidance regarding the better development of bicycle-sharing systems and bicycle-transit integration, it is extremely necessary to understand travelers' choice behaviors and attitudes towards shared bicycles. The research content, method, and results in this study can be applicable for those international cities where bicycle-sharing systems are newly introduced.

Bicycle-sharing systems also attracted increasing attention in USA in recent years. As an auto-oriented country, daily trips in most cities of USA have been dominated by private vehicles for many years. Lots of programs have been explored by the government and transit agencies to enhance attractiveness of public transit, such as installing bicycle racks on bus, allowing bicycles to board trains, and providing shuttle services to metro station. As the big success of bicyclesharing systems in the world over the past few years, shared bicycles are regarded as one of the most promising strategies to solve public transport problems. Bicycle-transit integration has been widely implemented and investigated in USA. The 
mode share of cycling has increased in some cities like New York [56] and Washington, DC [57]. However, most researches about travel behavior of cyclists using bicyclesharing systems are based on actual travel data. Few studies focus on travelers' preference, attitudes, and the reasons many people do not use shared bicycles. It is extremely important to understand travelers' real needs to propose feasible and effective improvement plans. This study also sheds light on analytical process of travelers' choice behaviors and improvement directions for bicycle-sharing systems in countries where bicycle-sharing systems are under increasing development and improvement. Through before- and aftertravel behavior analysis, combined with actual bicycle travel data, the transport manager can get more details about the number of bicycle travelers attracted by shared bicycles, the reason why some people decline to ride it, and which aspects need to be improved from the perspective of travelers themselves. Bicycle-sharing systems have been implemented for more than 50 years in Europe and are well developed. Bicycle-transit integration also makes a big success. But it is also necessary and important to investigate travelers' beforeand after-shared-bicycle introduction mode preference for cities where bicycle-sharing systems are newly introduced.

The study has some limitations in methodology, factors included, and questionnaire design. In this paper, the traditional logit model was used. More advanced travel behavioral models such as Latent Class Model (LCM) can be introduced to improve model fitness. More influencing factors can be excavated and included in the model. Some studies demonstrated that other built environments such as shade and bikeway [58], weather indicators including temperature and rain [59], and road congestion [59] have significant effect on travel choice. These factors may satisfactorily represent the nonexplained parts in the proposed model. In addition, the choice behaviors of access and egress trips may be different. According to Givoni and Rietveld (2007) [60], bicycle mode share was much higher at the home-end than the activity-end for the access/egress trip. Other related researches also proved similar conclusion. However, in their research context, it is difficult for travelers to find available bicycles at the activityend, except that they park a bicycle at the activity-end, or bicycles are allowed to board on the bus or train [61]. In most of Chinese cities, shared bicycles are widely distributed in the urban area and are easy to be found. So, if the access/egress trips are distinguished, the expected results may be as follows: before the introduction of bicycle-sharing systems, walk, private bicycle, and automobile is still the preference order, but private bicycle mode share at the home-end may be much higher than that at the activity-end; after the introduction of bicycle-sharing systems, both the preference orders of access and egress trips are dependent on the location of home and activity (in the suburban area or urban area).

Further research could focus on the following aspects. (1) Modality style (specified as latent classes) acts as an important indicator of the repetitive nature of travel choice [62]. Class membership model could be introduced; then, the influence of modality style on travel mode choice for first/last mile trips can be analyzed. (2) The impacts of the built environment on travel choice behavior have been paid great attention in recent years. More built environment factors such as green shade and the length of bicycle lanes should be considered in the travel choice model for first/last mile trips in the future. (3) The comparison analysis of mode preference between access/egress trips at the home side and activity side will be an interesting research on the basis of present questionnaire improvement. (4) In order to validate the effects of bicyclesharing systems on travel patterns effectively, a case study could be conducted to compare travel choice behavior in scenarios of successful bicycle-transit integration and no bicycle-sharing systems integration with public transport.

\section{Data Availability}

The data used to support the findings of this study are available from the first author upon request (the information of first author: Aihua Fan, crystalfanzjh@sina.com).

\section{Conflicts of Interest}

The authors declare that there are no conflicts of interest.

\section{Acknowledgments}

The authors would like to acknowledge Editage (www.editage .com) for English language editing. This paper was prepared with the support of the National Natural Science Foundation of China (NSFC) under Grant no. 71871013.

\section{References}

[1] N. Tilahun, P. V. Thakuriah, M. Li, and Y. Keita, "Transit use and the work commute: Analyzing the role of last mile issues," Journal of Transport Geography, vol. 54, pp. 359-368, 2016.

[2] C. C. Huang, "Crack the "last mile" problem of urban traffic," Traffic \& Transportation, vol. 1, pp. 106-109, 2013 (Chinese).

[3] J. Weng, P. Lin, Q. Liang, D. Alivanistos, and S. Ma, "The impact of weather condition and built environment on public bikesharing trips in Beijing," in Proceedings of the 97th Annual Meeting of the Transportation Research Board, pp. 1-6, Washington DC, USA, 2018.

[4] iResearch, "Research report of bicycle-sharing industry of China" (Chinese), 2017.

[5] "The number of shared bicycles needed in Beijing: a lack of nearly millions" (Chinese), http://tech.sina.com.cn/roll/201708-20/doc-ifykcirz3263342.shtml, 2018.

[6] Mobike Company and Beijing Tsinghua United Planning and Design Institute LTD (T-H-U-P-D-I), "White paper of shared bike and urban development" (Chinese), 2017.

[7] G. Wang, S. Liu, and Y. Xia, "Sharing bike and urban sustainable development," Urban Transportation of China, vol. 15, no. 3, pp. 90-97, 2017 (Chinese).

[8] G. K. Kuah and J. Perl, "Opyimization of feeder bus routes and bus-stop spacing," Journal of Transportation Engineering, vol. 114, no. 3, pp. 341-354, 1988.

[9] P. Shrivastava and M. O’Mahony, "Design of feeder route network using combined genetic algorithm and specialized repair heuristic," Journal of Public Transportation, vol. 10, no. 2, pp. 109-133, 2007. 
[10] X. Li and L. Quadrifoglio, "Optimal zone design for feeder transit services," Transportation Research Record, no. 2111, pp. 100-108, 2009.

[11] X. Li and L. Quadrifoglio, "2-Vehicle zone optimal design for feeder transit services," Public Transport, vol. 3, no. 1, pp. 89104, 2011.

[12] M. Replogle, "Bicycle access to public transportation: learning from abroad," Transportation Research Record, vol. 1396, pp. 7580, 1992.

[13] J.-R. Lin and T.-H. Yang Ta-Hui, "Strategic design of public bicycle sharing systems with service level constraints," Transportation Research Part E: Logistics and Transportation Review, vol. 47, no. 2, pp. 284-294, 2011.

[14] R. Nair and E. Miller-Hooks, "Equilibrium network design of shared-vehicle systems," European Journal of Operational Research, vol. 235, no. 1, pp. 47-61, 2014.

[15] L. Yang, Z. Ning, and M. Feng, "Simultaneous optimization of transit network and public bicycle station network," Journal of Central South University, vol. 22, no. 4, pp. 1574-1584, 2015.

[16] M. Replogle, "Bicycle access to public transportation: learning from abroad," Transportation Research Record, vol. 1396, pp. 7580, 1993.

[17] J. Doolittle and E. Porter, Integration of Bicycles and Transit. Publication Transit Cooperative Research Program-TCRP Synthesis 4, 1994.

[18] P. DeMaio, "Bike-sharing: history, impacts, models of provision, and future," Journal of Public Transportation, vol. 12, no. 3, pp. 41-56, 2009.

[19] B. Caulfield, M. O’Mahony, W. Brazil, and P. Weldon, "Examining usage patterns of a bike-sharing scheme in a medium sized city," Transportation Research Part A: Policy and Practice, vol. 100, pp. 152-161, 2017.

[20] State Information Center and Internet Society of China, Annual Report of China Sharing Economy Development, 2018.

[21] D. Rojas-Rueda, A. De Nazelle, M. Tainio, and M. J. Nieuwenhuijsen, "The health risks and benefits of cycling in urban environments compared with car use: Health impact assessment study," British Medical Journal, vol. 343, no. 7819, Article ID d4521, pp. 1-8, 2011.

[22] E. Fishman, S. Washington, and N. Haworth, "Bike share's impact on car use: Evidence from the United States, Great Britain, and Australia," Transportation Research Part D: Transport and Environment, vol. 31, pp. 13-20, 2014.

[23] W. Zhu, Y. Pang, D. Wang, and X. Yu, "Travel behavior change after the introduction of public bicycle systems: a case study of Minhang District, Shanghai," Urban Panning Forum, vol. 5, pp. 76-81, 2012 (Chinese).

[24] P. Zhao and S. Li, "Bicycle-metro integration in a growing city: The determinants of cycling as a transfer mode in metro station areas in Beijing," Transportation Research Part A: Policy and Practice, vol. 99, pp. 46-60, 2017.

[25] S. Susan and M. Elliot, "Unraveling the modal impacts of bikesharing," Access Magazine, vol. 1, no. 47, pp. 7-15, 2015.

[26] R. Wang and C. Liu, "Bicycle-transit integration in the United States, 2001-2009," Journal of Public Transportation, vol. 16, no. 3, pp. 95-119, 2013.

[27] R. Kager, L. Bertolini, and M. Te Brömmelstroet, "Characterisation of and reflections on the synergy of bicycles and public transport," Transportation Research Part A: Policy and Practice, vol. 85, pp. 208-219, 2016.
[28] R. Kager and L. Harms, "Synergies from improved cyclingtransit integration: towards an integrated urban mobility system," in Proceedings of the International Transport Forum, pp. 1-36, Tokoyo, Japan, 2017.

[29] S. Shelat, R. Huisman, and N. van Oort, "Analysing the trip and user characteristics of the combined bicycle and transit mode," Research in Transportation Economics, vol. 69, pp. 68-76, 2018.

[30] M. Saberi, M. Ghamami, Y. Gu, M. Shojaei, and E. Fishman, "Understanding the impacts of a public transit disruption on bicycle sharing mobility patterns: A case of Tube strike in London," Journal of Transport Geography, vol. 66, pp. 154-166, 2018.

[31] K. B. Campbell and C. Brakewood, "Sharing riders: How bikesharing impacts bus ridership in New York City," Transportation Research Part A: Policy and Practice, vol. 100, pp. 264-282, 2017.

[32] E. W. Martin and S. A. Shaheen, "Evaluating public transit modal shift dynamics in response to bikesharing: a tale of two U.S. cities," Journal of Transport Geography, vol. 41, pp. 315-324, 2014.

[33] L. L. P. Puello and K. Geurs, "Modelling observed and unobserved factors in cycling to railway stations: Application to transit-oriented-developments in the Netherlands," European Journal of Transport and Infrastructure Research, vol. 15, no. 1, pp. 27-50, 2015.

[34] S. Mohanty, S. Bansal, and K. Bairwa, "Effect of integration of bicyclists and pedestrians with transit in New Delhi," Transport Policy, vol. 57, pp. 31-40, 2017.

[35] Beijing Municipal Bureau Statistics and National Bureau of Statistics Survey Office in Beijing, Beijing statistical yearbook, 2017.

[36] Beijing Public Transport, Social Responsibility Report of Beijing Public Transport in 2017, 2018.

[37] China Metros, Statistical Analysis and Reporting of Urban Rail Transit in 2017, 2018.

[38] Beijing Transport Institute, Annual report of Beijing transport development in 2012, 2013.

[39] Beijing Transport Institute, Annual Report of Beijing Transport Development in 2016, 2017.

[40] P. Cozy and S. Bates, Methods in Behavioral Research, McGrawHill Education, 2014.

[41] S. Müller, S. Tscharaktschiew, and K. Haase, "Travel-to-school mode choice modelling and patterns of school choice in urban areas," Journal of Transport Geography, vol. 16, no. 5, pp. 342357, 2008.

[42] X. He and W. Liu, Applied Regression Analysis, China Renmin University Press, 2015.

[43] T. Munshi, Built form, travel behavior and low carbon development in Ahmedabad, India [PhD thesis], University of Twente, Netherlands, 2013.

[44] X. Wang, Research on traffic engineering design based on travel characteristics, South China University of Technology, Guangzhou, China, 2014 (Chinese).

[45] J. Mi, Research on travel mode choice of urban residents considering trip costs, Southwest Jiaotong University, Chengdu, China, 2015 (Chinese).

[46] Y. Muromachi, "Experiences of past school travel modes by university students and their intention of future car purchase," Transportation Research Part A: Policy and Practice, vol. 104, pp. 209-220, 2017.

[47] T. Kuhnimhof, R. Buehler, M. Wirtz, and D. Kalinowska, "Travel trends among young adults in Germany: Increasing 
multimodality and declining car use for men," Journal of Transport Geography, vol. 24, pp. 443-450, 2012.

[48] H. Du, "Rich dad, poor dad: the impact of family background on educated young people's migration from peripheral China," Journal of Youth Studies, vol. 21, no. 1, pp. 90-110, 2018.

[49] G. Circella, F. Alemi, K. Tiedeman et al., What Affects Millennials' Mobility? PART II: The Impact of Residential Location, Individual Preferences and Lifestyles on Young Adults' Travel Behavior in California, 2017.

[50] J. Zhu and Y. Fan, "Daily travel behavior and emotional wellbeing: Effects of trip mode, duration, purpose, and companionship," Transportation Research Part A: Policy and Practice, vol. 118, pp. 360-373, 2018.

[51] R. Ye and H. Titheridge, "Satisfaction with the commute: The role of travel mode choice, built environment and attitudes," Transportation Research Part D: Transport and Environment, vol. 52, pp. 535-547, 2017.

[52] Z. Mao, D. Ettema, and M. Dijst, "Commuting trip satisfaction in Beijing: Exploring the influence of multimodal behavior and modal flexibility," Transportation Research Part A: Policy and Practice, vol. 94, pp. 592-603, 2016.

[53] E. A. Morris and E. Guerra, "Mood and mode: does how we travel affect how we feel?” Transportation, vol. 42, no. 1, pp. 2543, 2014.

[54] J. De Vos, P. L. Mokhtarian, T. Schwanen, V. Van Acker, and F. Witlox, "Travel mode choice and travel satisfaction: bridging the gap between decision utility and experienced utility," Transportation, vol. 43, no. 5, pp. 771-796, 2016.

[55] "Beijing will suspend more shared bike into market" (Chinese), http://www.xinhuanet.com/politics/2017-09/08/c_1121626334 .htm, 2017.

[56] S. Kaufman, L. Koven, N. Levenson, and M. Moss, Citi Bike: the first two years, The Rudin Center for Transportation Policy and Management, 2015.

[57] D. Buck, R. Buehler, P. Happ, B. Rawls, P. Chung, and N. Borecki, "Are bikeshare users different from regular cyclists? A first look at short-term users, annual members, and area cyclists in the Washington, D.C., region," Transportation Research Record: Journal of the Transportation Research Board, vol. 2387, no. 1, pp. 112-119, 2013.

[58] L. Fu and S. Farber, "Bicycling frequency: A study of preferences and travel behavior in Salt Lake City, Utah," Transportation Research Part A: Policy and Practice, vol. 101, pp. 30-50, 2017.

[59] A. A. Campbell, C. R. Cherry, M. S. Ryerson, and X. Yang, "Factors influencing the choice of shared bicycles and shared electric bikes in Beijing," Transportation Research Part C: Emerging Technologies, vol. 67, pp. 399-414, 2016.

[60] M. Givoni and P. Rietveld, "The access journey to the railway station and its role in passengers' satisfaction with rail travel," Transport Policy, vol. 14, no. 5, pp. 357-365, 2007.

[61] K. Halldórsdóttir, O. A. Nielsen, and C. G. Prato, "Home-end and activity-end preferences for access to and egress from train stations in the Copenhagen region," International Journal of Sustainable Transportation, vol. 11, no. 10, pp. 776-786, 2017.

[62] A. Vij, A. Carrel, and J. L. Walker, "Incorporating the influence of latent modal preferences on travel mode choice behavior," Transportation Research Part A: Policy and Practice, vol. 54, pp. 164-178, 2013. 


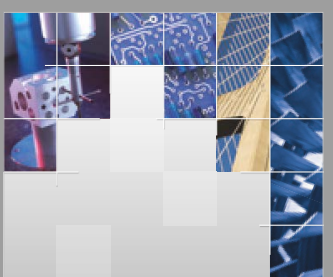

\section{Enfincering}
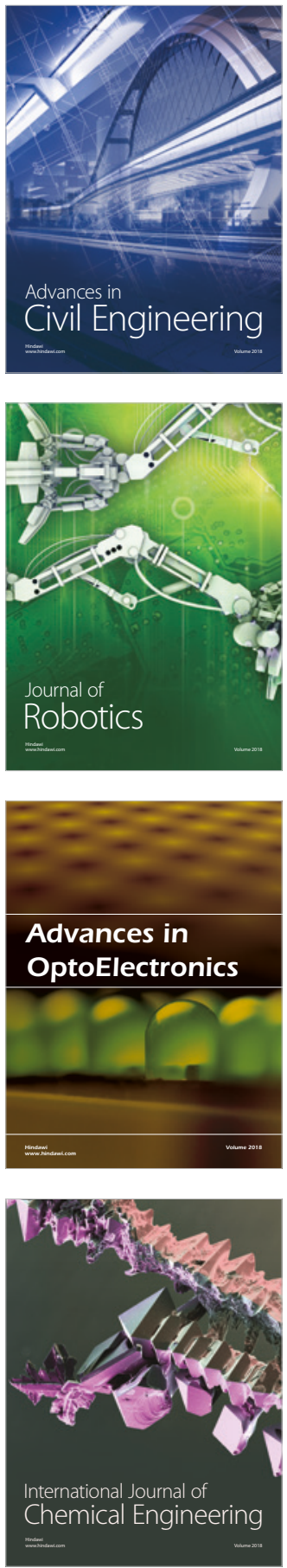

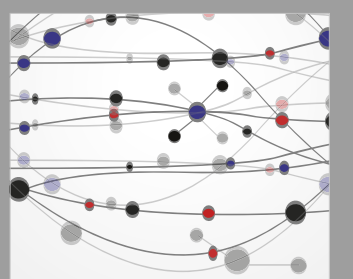

\section{Rotating \\ Machinery}

The Scientific World Journal

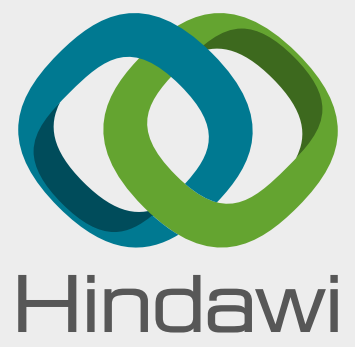

Submit your manuscripts at

www.hindawi.com
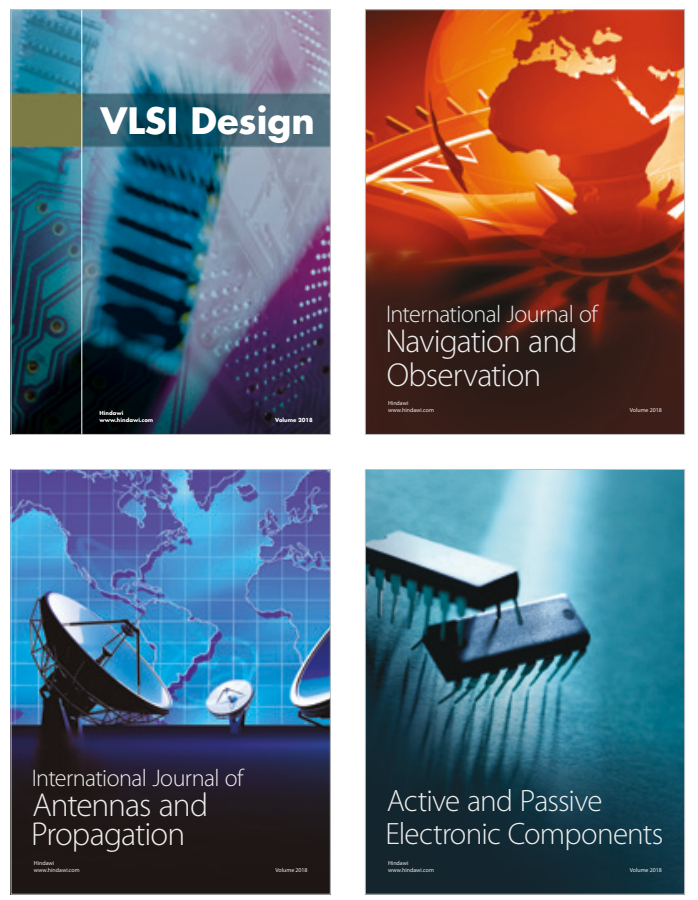
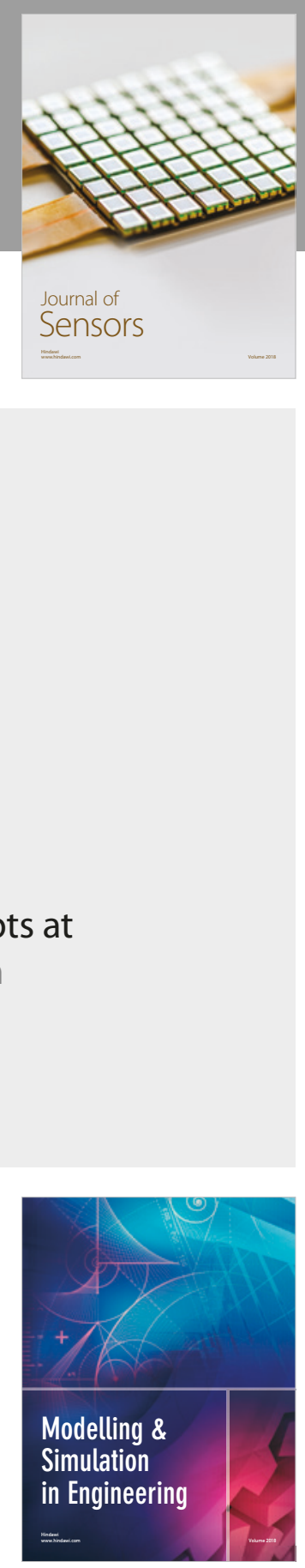

\section{Advances \\ Multimedia}
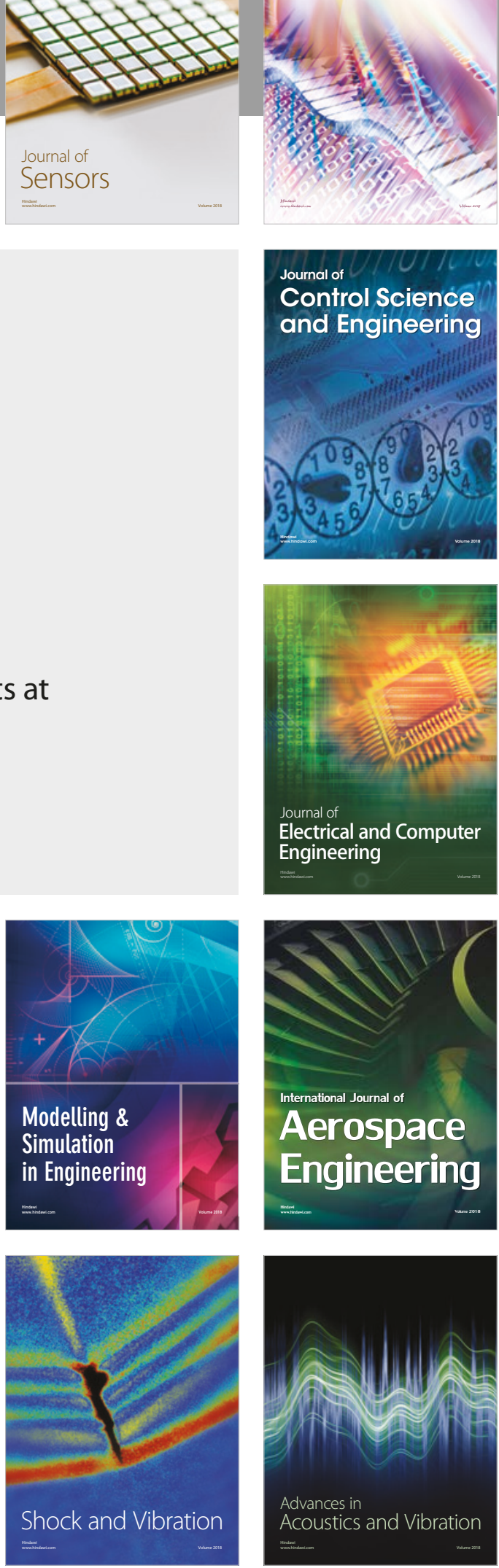